\title{
Percepciones y Valoraciones de Alumnos en Edad Escolar sobre su Experiencia de Aprendizaje en un Programa Semipresencial de Lengua y Cultura Españolas
}

\author{
Sara Garcia Martinez ${ }^{1}$ \\ ${ }^{1}$ Doutoranda no Departamento de Didática da UNED - Calle de Juan del Rosal, 14, 28040 Madrid Espanha. \\ sara.alceny@gmail.com
}

\section{Resumen}

En este artículo se presenta el análisis de las valoraciones realizadas por el alumnado de un programa de enseñanza de lengua y cultura españolas que utiliza la modalidad semipresencial, sobre sus experiencias de aprendizaje en línea durante el curso 2014-15, referidas a frecuencia y autonomía de trabajo, percepción de dificultad y preferencias sobre actividades y modalidad de enseñanza, entre otros aspectos. El objetivo del estudio es obtener un feedback de los destinatarios de los cursos $(\mathrm{N}=7.044)$ que ayude a la toma de decisiones en su diseño y revisión tras el segundo año de implementación. El estudio se enmarca en un programa de enseñanza denominado ALCE (Agrupaciones de Lengua y Cultura Españolas), del Ministerio de Educación, ofrecido a alumnos españoles residentes en el exterior y en edad escolar, para contribuir al mantenimiento de sus vínculos con la lengua y cultura españolas. Los resultados señalan, entre otros aspectos, la preferencia del alumnado hacia actividades relacionadas con destrezas visuales y auditivas, la conveniencia de reducir las incidencias técnicas, el aumento del nivel de autonomía de trabajo en relación a la edad y, en general.

Palavras-chave: Enseñanza semipresencial, Blended learning, Cursos en línea, Actividades en línea, Moodle, Tecnologías de la información y la comunicación, Percepciones del alumnado. 


\title{
Perceptions and Appraisals of K-12 Students about their Learning Experiences in A Spanish Language and Culture B- Learning Program
}

\begin{abstract}
In this article we present the analysis of the appraisals declared by students of a blended learning Spanish Language and Cultural program about their experiences during 201415 academic year in terms of their online learning habits and autonomy, perception of difficulty and preference on activities and learning modality, among others. The purpose of this study is to receive a feedback from the students $(\mathrm{N}=7.000)$ after the second year of b-learning implementation. The study takes place in the program Agrupaciones, framed on the education policies that the Government of Spain provides to Spanish K12 students living abroad, through complementary courses, in order to maintain their language and cultural of origin. Results in the study show students' preference for activities related to visual and listening skills, the convenience of reducing technical issues during the performance of the LMS activities, increasing levels of learning autonomy of students through age, and in general terms, students' satisfaction with blearning modality.
\end{abstract}

Keywords: B-learning, Online courses, Online activities, Moodle, Technologies of the information and the communication, Moodle, Students' perceptions. 


\section{Introducción}

Los modelos de enseñanza semipresencial, que combinan la instrucción presencial con la instrucción a distancia mediada por el ordenador, también denominados modelos de blended learning o b-learning, mixtos o combinados, son cada vez más frecuentes en las instituciones educativas. Existen numerosas referencias sobre la tendencia de expansión de estos modelos, contextualizadas tanto en EEUU (Singh, 2006; Skater, 2011; Graham, 2013; Clark y Barbour, 2015), como en España (Bricall, 2000; Area, Sanabria y González, 2008; de Cos, 2009; Pallisé, 2013; López, Sobrino, Barrajón y Gallego, 2013; Pedró, 2015).

La finalidad de los modelos semipresenciales es, en términos generales, que las dos modalidades intervinientes, presencial y en línea, se complementen mutuamente (Poon, 2013), de manera que las debilidades de una modalidad puedan ser compensadas por las fortalezas de la otra (Osguthorpe y Graham, 2003), o dicho en otras palabras, "utilizar lo mejor de ambos mundos" (Graham y Dziuban, 2008, p. 270) logrando un balance efectivo entre ellos (Brook, Beauchamp y Campus, 2015) y maximizando los beneficios de ambas (Osguthorpe y Graham, 2003).

En España, la etapa que ha experimentado en mayor grado la tendencia de expansión de estos modelos es la educación universitaria, quedando reflejada en investigaciones sobre experiencias en este contexto (Torrandell y Noguera, 1999, Nó, 2005; Griful, Gibert y Salam, 2005; Area et al. 2008, 2010; Toboso, 2010, Galán y Rodríguez, 2012). Encontramos también una incipiente oferta formativa de semipresencialidad y documentación sobre experiencias en enseñanzas regladas de educación permanente, como la formación de adultos en secundaria (ESPA) ${ }^{12}$ (López, Flores y González, 2012; Fernández, 2013; Acín, 2014) o en las enseñanzas de idiomas³. Sin embargo, la documentación de investigaciones de modelos de b-learning con alumnado en edad escolar es menos frecuente. De modo general, Clark y Barbour (2015) señalan la necesidad de una mayor investigación sobre las modalidades online, blended y a distancia dentro de la etapa de la educación primaria y secundaria obligatoria, tanto en Estados Unidos como a nivel mundial. En este último país, Halverson, Graham, Spring y Drysdale (2012) cuantifican en un 66,1\% las investigaciones sobre b-learning referidas a la educación universitaria; alrededor de un $20 \%$ no se definen en una etapa determinada, un $12,5 \%$ se centran en la formación corporativa (empresas privadas) y solo un $1,8 \%$ lo estarían en el campo la etapa K-124. En Drysdale et al. (2013), los 
mismos autores vuelven a confirmar esta idea, cuantificando en un $8 \%$ los estudios de postgrado centrados en la franja de 6-12 años, donde concluyen que se encuentra uno de los vacíos de estudio significativos en b-learning. En España, Pedró (2015, p. 92), reconoce el adelanto que las instituciones universitarias llevan a las escolares sobre la incorporación y aprovechamiento de las tecnologías, aludiendo a la "dificultad de documentar una expansión tan rápida y generalizada de innovaciones pedagógicas soportadas por la tecnología con los niveles de adopción que se dan en la enseñanza universitaria".

Dentro de las seis áreas de investigación emergentes en b-learning presentadas por Graham (2013)5: marco teórico de b-learning, efectividad de la enseñanza en esta modalidad en comparación con la puramente presencial o en línea, acceso y flexibilidad, satisfacción del alumnado, satisfacción del profesorado, y costes de implementación, el presente estudio se centra en el tercero de ellos, el alumnado, en relación a su experiencia, percepciones y disposiciones hacia las actividades en línea y hacia el modelo semipresencial.

Una de las clasificaciones más completas de los modelos de b-learning en la etapa escolar consideramos que es la propuesta por Skater y Horn $(2012)^{6}$, quienes a través del estudio de más de un centenar de este tipo de programas y de la identificación y combinación de seis variables (ubicación del proceso de enseñanza-aprendizaje, distribución del contenido, agrupamientos, formas de instrucción, tipos de instructores y formas de tutorización) categorizan los modelos en cuatro: rotatorio, flexible, "a la carta" y virtual enriquecido. De estos modelos, el utilizado en el programa objeto de estudio se encuadraría dentro del grupo "Modelo a la carta" y cuya adaptación gráfica se expone en la Figura 1.

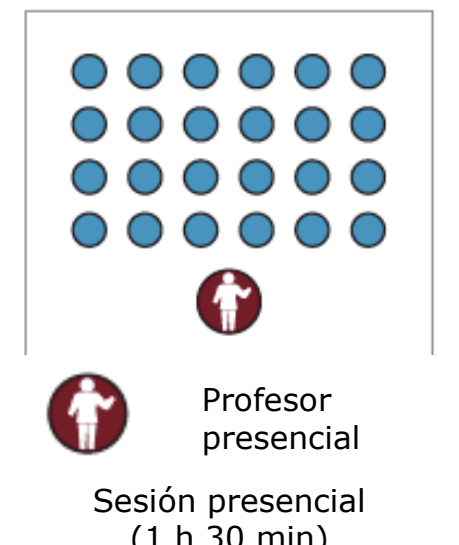

(1 h 30 min)

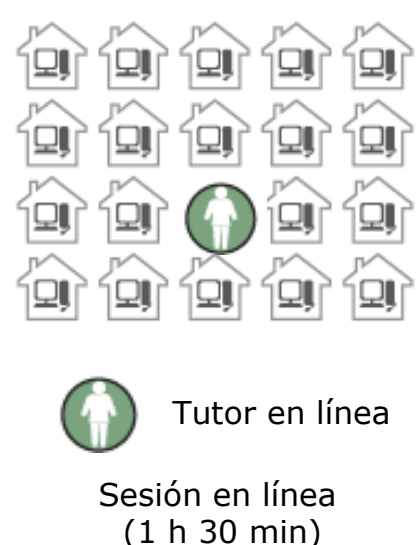

(1 h $30 \mathrm{~min}$ )

Figura 1: Modelo de enseñanza semipresencial utilizado en el programa. Adaptación del "Modelo a la carta" según la categorización de Skater y Horn (2012) 


\section{Contexto}

El presente estudio se enmarca en un programa de enseñanza de lengua y cultura españolas, denominado ALCE (Agrupaciones de Lengua y Cultura españolas), del Ministerio de Educación, Cultura y Deporte, dirigido a alumnos de entre 7 y 17 años de edad y que se desarrolla en ocho países (Suiza, Alemania, Francia, Reino Unido, Países Bajos, Bélgica, EEUU, Canadá y Australia). La finalidad de estas enseñanzas es el "mantenimiento de los vínculos de los ciudadanos españoles residentes en el exterior con su lengua y cultura de origen", orientándose específicamente "a la consecución del adecuado nivel de competencia lingüística, al conocimiento de la realidad sociocultural española y al enriquecimiento cultural" 7 . El carácter de estas enseñanzas es complementario y se desarrolla en horario extraescolar.

La implantación de la semipresencialidad en el programa ALCE comienza en el curso 2013-14, desde los niveles iniciales del programa y su vía de adopción se realiza mediante la inclusión de la modalidad en línea a unas enseñanzas presenciales ya existentes, vía que, según Bliuc, Goodyear y Ellis (2007), es la utilizada de manera mayoritaria por las instituciones educativas. Para ello fue necesaria una reducción organizativa en el tiempo de instrucción presencial y su correspondiente sustitución por instrucción en línea, aspecto clave para Dziuban, Hartman y Moskal (2004) a la hora de considerar un programa de blearning. La distribución temporal resultante en la normativa actual del programa es del $50 \%$ en cada modalidad (una hora y media semanal presencial y una hora y media en línea).

Las enseñanzas en línea del programa se imparten a través de la plataforma Moodle, en un espacio denominado Aula Internacional http://mecd.es/cidead/alce2, cuyo servidor se ubica técnicamente en el CIDEAD (Centro para la Innovación y Desarrollo de la Educación a Distancia) de la Subdirección General de aprendizaje a lo largo de la vida del Ministerio de Educación, Cultura y Deporte. En dicho espacio se alojaron en $2014 / 15$ los 70 cursos y matriculados los alumnos ( $N=7.044)$ objeto de este estudio.

\section{Metodología}

\subsection{Instrumento}

El instrumento utilizado para la recogida de datos es un cuestionario diseñado ad hoc. Las encuestas o cuestionarios constituyen una herramienta de obtención de 
información muy habitual en el campo de la investigación educativa y ofrecen la posibilidad de describir y analizar "opiniones, actitudes, habilidades, (...) de amplias muestras representativas de población definidas" (Martínez Mediano, 2004, p. 255), por lo que consideramos que la elección de este instrumento encaja con la finalidad del presente estudio.

La versión inicial del instrumento se somete a validación por grupo de expertos, obteniéndose índices de pertinencia y adecuación positivos ( $\bar{x} 4,67$ y $\bar{x} 4,46$, sobre escala de 5, respectivamente). Se realizan las modificaciones oportunas, resultando en su versión final una encuesta de 14 ítems, 11 de respuesta cerrada y 3 de respuesta abierta, entre las que se incluye una de opinión voluntaria para los padres de alumnos. La encuesta se aplica dentro de cada uno de los 70 cursos en línea del programa, como una actividad para todos los alumnos, con carácter final del curso 2014-15 y voluntario.

\subsection{Población}

El cuestionario se dirige específicamente al alumnado de los niveles $A 1, A 2.1, A 2.2$ y B1.1, cuyas edades oscilan entre 7 y 15 años, lo cual determina el diseño y redacción de los ítems en cuanto a nivel de abstracción y lenguaje utilizado en las preguntas, además de nivel del competencia lingüística del español, ya que en algunos casos no es la lengua materna de los alumnos. Todas estas circunstancias suponen un reto a la hora de redactar preguntas sobre aspectos relativos a la conciencia de su aprendizaje.

\subsection{Cuestiones de estudio}

La cuestiones de estudio básicas en las que ese estructura el cuestionario son:

- Frecuencia de trabajo semanal: ¿Realizan las actividades en línea, programadas para una duración de una hora y media semanal, en diferentes días o en uno solo?

- Grado de autonomía: ¿Realizan las actividades ellos solos o reciben la ayuda de una persona mayor? Si reciben ayuda, ¿es en todo momento o puntualmente?

- Percepción sobre la dificultad de las actividades en línea: Las actividades propuestas en cada curso, ¿les resultan fáciles o difíciles de realizar? ¿han experimentado dificultades/incidencias técnicas?

- Percepción sobre su aprendizaje en línea. ¿Consideran que han aprendido, de manera general, con las actividades de los cursos en línea? 
- Preferencias y gustos por actividades y modalidad de aprendizaje: ¿Les han gustado las actividades de Aula Internacional?, ¿Qué tipos de actividades les gustan más? ¿Y las que menos?, ¿Qué prefieren, ir a clase con sus compañeros o realizar las actividades en línea, o las dos cosas?

Además de estas cuestiones de estudio, al inicio de la encuesta se incluyen dos ítems de perfil, referidos a edad y sexo, y otro sobre experiencia previa en los cursos de Aula Internacional. En el volcado de datos se recoge de forma indirecta información sobre el país y nivel de procedencia de la respuesta, que será utilizada posteriormente para análisis comparativos entre diferentes subgrupos.

\section{Resultados}

\subsection{Análisis de la participación en la encuesta.}

El índice de participación global obtenido en la encuesta fue del 41,3\% ( $N=7.044$, $\mathrm{n}=2.906)$, resultando un margen de confianza del $95 \%$ y un rango de error máximo de un $4 \%$, por lo que podríamos hablar de valores observados con alto nivel de generalización para el programa en los análisis e interpretaciones realizados a nivel global (Tablas 2 y 3 ).

Tabla 2: Participación en la encuesta, por países.

\begin{tabular}{l|c|c|c} 
& $\begin{array}{c}\text { Alumnos } \\
\text { participantes en la } \\
\text { encuesta }\end{array}$ & $\begin{array}{c}\text { Alumnos } \\
\text { matriculados }\end{array}$ & $\begin{array}{c}\% \text { de } \\
\text { participación, por } \\
\text { países }\end{array}$ \\
\hline Suiza & 889 & 2.031 & $44 \%$ \\
\hline Alemania & 582 & 1.282 & $45 \%$ \\
\hline Reino & 351 & 982 & $36 \%$ \\
Unido & 328 & 644 & $51 \%$ \\
\hline Bélgica & 327 & 464 & $70 \%$ \\
\hline EEUU & 312 & 1.331 & $23 \%$ \\
\hline Francia & 117 & 310 & $38 \%$ \\
\hline Holanda & $\mathbf{2 . 9 0 6}$ & $\mathbf{7 . 0 4 4}$ & $\mathbf{4 1 , 3 \%}$ \\
\hline Total & & &
\end{tabular}

Tabla 3: Participación en la encuesta, por niveles.

\begin{tabular}{l|r|r|r|r|r}
\multirow{2}{*}{} & \multicolumn{4}{|c|}{ Nivel } & \multirow{2}{*}{ Total } \\
\cline { 2 - 6 } & $\mathrm{A} 1$ & $\mathrm{~A} 2.1$ & $\mathrm{~A} 2.2$ & $\mathrm{~B} 1.1$ & \\
\hline $\begin{array}{l}\text { Alumnos participantes en la } \\
\text { encuesta }\end{array}$ & 874 & 845 & 778 & 409 & 2.906 \\
\hline Alumnos matriculados & 1.984 & 1.887 & 1.701 & 1.472 & 7.044 \\
\hline \% de participación, por nivel & $44 \%$ & $45 \%$ & $46 \%$ & $28 \%$ & $41,3 \%$ \\
\hline
\end{tabular}




\subsection{Análisis del perfil de los encuestados y de su experiencia previa en Aula Internacional.}

La distribución obtenida en los datos de perfil de los encuestados por sexo es muy equitativa: $51 \%$ niñas $(n=1.485)$ y $49 \%$ niños $(n=1.421)$.

Por edad (Tabla 4) se observa una gran predominancia de los alumnos de edades entre 7 y 11 años, franja que recoge al 96\% de los participantes. Las dos edades más frecuentes son los 8 y 9 años ( $27 \%$ y 26\%, respectivamente). En la distribución de edad por niveles académicos en el programa se observa la predominancia de dos edades específicas en cada uno de ellos, de forma correlativa y ascendente (predominancia de 7 y 8 años en el nivel A1; 8 y 9 años en A2.1, etc. -con sombreado gris en la tabla), alcanzando ambos subgrupos sumatorios en torno al $80 \%$ (ver última fila) $y$ correspondiéndose en un alto grado con las edades orientativas expuestas en la normativa del programa para la adscripción del alumnado a cada uno de estos cuatro niveles de competencia lingüística.

Tabla 4: Distribución de los participantes por niveles y edad.

\begin{tabular}{|c|c|c|c|c|c|c|c|c|c|c|c|}
\hline \multirow{3}{*}{$\begin{array}{c}\text { Edad } \\
7\end{array}$} & \multicolumn{8}{|c|}{ Nivel } & & & \\
\hline & \multicolumn{2}{|c|}{$\mathrm{A} 1$} & \multicolumn{2}{|c|}{ A2.1 } & \multicolumn{2}{|c|}{ A2.2 } & \multicolumn{2}{|c|}{ B1.1 } & \multicolumn{3}{|c|}{ Total } \\
\hline & 317 & $36.3 \%$ & 21 & $2.5 \%$ & 2 & $0.3 \%$ & 1 & $0.2 \%$ & 341 & $11.7 \%$ & \multirow{5}{*}{$96 \%$} \\
\hline 8 & 451 & $51.6 \%$ & 306 & $36.2 \%$ & 38 & $4.9 \%$ & 2 & $0.5 \%$ & 797 & $27.4 \%$ & \\
\hline 9 & 75 & $8.6 \%$ & 390 & $46.2 \%$ & 274 & $35.2 \%$ & 17 & $4.2 \%$ & 756 & $26.0 \%$ & \\
\hline 10 & 20 & $2.3 \%$ & 79 & $9.3 \%$ & 346 & $44.5 \%$ & 153 & $37.4 \%$ & 598 & $20.6 \%$ & \\
\hline 11 & 5 & $0.6 \%$ & 31 & $3.7 \%$ & 80 & $10.3 \%$ & 187 & $45.7 \%$ & 303 & $10.4 \%$ & \\
\hline 12 & 3 & $0.3 \%$ & 9 & $1.1 \%$ & 20 & $2.6 \%$ & 36 & $8.8 \%$ & 68 & $2.3 \%$ & \multirow{4}{*}{$4 \%$} \\
\hline 13 & 3 & $0.3 \%$ & 5 & $0.6 \%$ & 14 & $1.8 \%$ & 9 & $2.2 \%$ & 31 & $1.1 \%$ & \\
\hline 14 & & $0.0 \%$ & 2 & $0.2 \%$ & 3 & $0.4 \%$ & 4 & $1.0 \%$ & 9 & $0.3 \%$ & \\
\hline 15 & & $0.0 \%$ & 2 & $0.2 \%$ & 1 & $0.1 \%$ & & $0.0 \%$ & 3 & $0.1 \%$ & \\
\hline Total & 874 & $100 \%$ & 845 & $100 \%$ & 778 & $100 \%$ & 409 & $100 \%$ & 2.906 & $100 \%$ & \\
\hline$\Sigma$ & & $87,9 \%$ & & $82,4 \%$ & & $79,7 \%$ & & $83,1 \%$ & & & \\
\hline
\end{tabular}

Los datos sobre la experiencia previa de los alumnos en los cursos en línea (Figura 2 y Tabla 5) señalan que el $41 \%$ de los alumnos han participado en Aula Internacional durante el curso 2014-15 por primera vez. Por niveles, se observa una diferencia fundamental el nivel A1 y el resto (93\% frente al 15, 22 y $23 \%$ en los otros tres niveles), datos que consideramos coherentes por ser A1 el curso inicial del programa.

Estos resultados constituyen una información útil de cara a que desde el equipo de diseño y revisión de los cursos se garantice en todos los niveles la inclusión de una información y soporte del tutor dirigida específicamente al alumnado nuevo, que en todos 
esos casos se enfrentan por primera vez al estudio de lengua y cultura a través de una modalidad de enseñanza novedosa para ellos, y con especial atención al nivel A1.

Tabla 5 y Figura 2 Experiencia previa en Aula Internacional, por niveles

\begin{tabular}{|c|c|c|c|c|c|}
\hline & \multicolumn{4}{|c|}{ Nivel } & \multirow{2}{*}{ Total } \\
\hline & A1 & A2.1 & A2. 2 & B1.1 & \\
\hline $\begin{array}{l}\text { Sí, este es el primer } \\
\text { curso que hago las } \\
\text { actividades de AI }\end{array}$ & $\begin{array}{c}813 \\
(93 \%)\end{array}$ & $\begin{array}{c}186 \\
(22 \%)\end{array}$ & $\begin{array}{c}116 \\
(15 \%)\end{array}$ & $\begin{array}{c}93 \\
(23 \%)\end{array}$ & $\begin{array}{l}1.208 \\
(41 \%)\end{array}$ \\
\hline $\begin{array}{l}\text { No, el curso pasado } \\
\text { también hice las } \\
\text { actividades de AI }\end{array}$ & $51(6 \%)$ & $\begin{array}{c}620 \\
(73 \%)\end{array}$ & $\begin{array}{c}620 \\
(80 \%)\end{array}$ & $\begin{array}{c}300 \\
(73 \%)\end{array}$ & $\begin{array}{l}1.591 \\
(55 \%)\end{array}$ \\
\hline No lo sé. & $10(1 \%)$ & $39(5 \%)$ & $42(5 \%)$ & $16(4 \%)$ & $107(4 \%)$ \\
\hline
\end{tabular}

¿Este es tu primer curso en Aula Internacional?

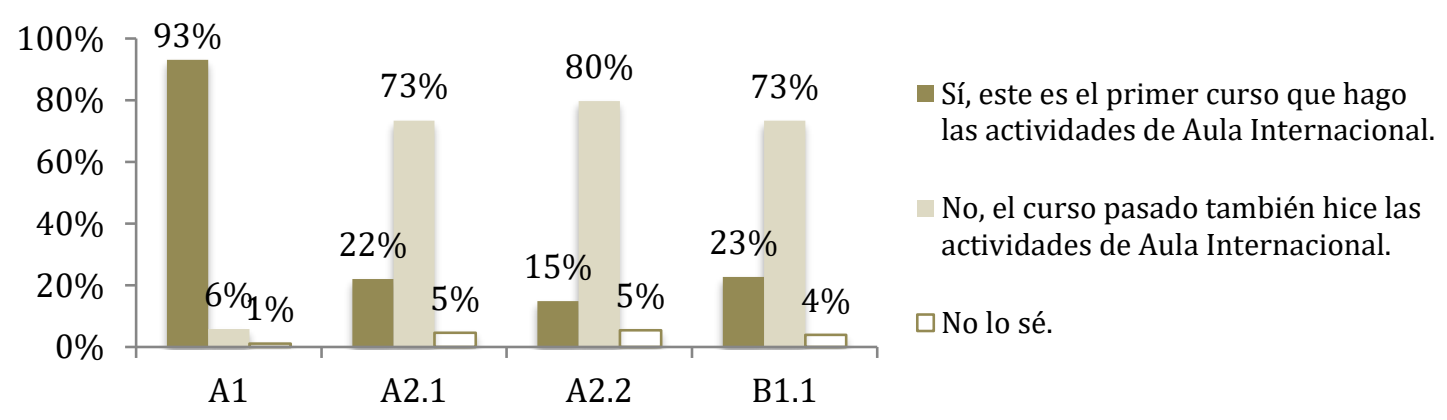

\subsection{Análisis de las cuestiones de estudio}

En relación a la frecuencia de trabajo de los alumnos con las actividades en línea desde sus casas, cuya duración se prevé en una hora y media semanal, según la normativa, se observa que las tres cuartas partes del alumnado total, el 76\%, las realiza en un solo día a la semana. Alrededor de un 20\% prefiere dividir el trabajo en dos días y solo un $5 \%$ de los participantes las realiza en más de dos días. Los resultados globales muestran una alta consistencia con los obtenidos por niveles. (Figura 3 y Tabla 6).

Tabla 6 / Figura 3: Frecuencia semanal de estudio para la realización de actividades en línea.

\begin{tabular}{|c|c|c|c|c|c|}
\hline & \multicolumn{4}{|c|}{ Nivel } & \multirow{2}{*}{ Total } \\
\hline & $\mathrm{A} 1$ & A2.1 & A2.2 & B1.1 & \\
\hline Un día a la semana & $\begin{array}{l}650 \\
(74 \%)\end{array}$ & $\begin{array}{l}637 \\
(75 \%)\end{array}$ & $\begin{array}{l}596 \\
(77 \%)\end{array}$ & $\begin{array}{l}321 \\
(78 \%)\end{array}$ & $2.204(76 \%)$ \\
\hline Dos días a la semana & $\begin{array}{l}184 \\
(21 \%)\end{array}$ & $\begin{array}{l}167 \\
(20 \%)\end{array}$ & $\begin{array}{l}143 \\
(18 \%)\end{array}$ & $74(18 \%)$ & $568(19 \%)$ \\
\hline $\begin{array}{l}\text { Más de dos días a la } \\
\text { semana }\end{array}$ & $40(5 \%)$ & $41(5 \%)$ & $39(5 \%)$ & $14(4 \%)$ & $134(5 \%)$ \\
\hline Total & 874 & 845 & 778 & 409 & $\begin{array}{l}2.906 \\
(100 \%)\end{array}$ \\
\hline
\end{tabular}


¿Cuántos días trabajas con el ordenador para realizar las actividades en línea?

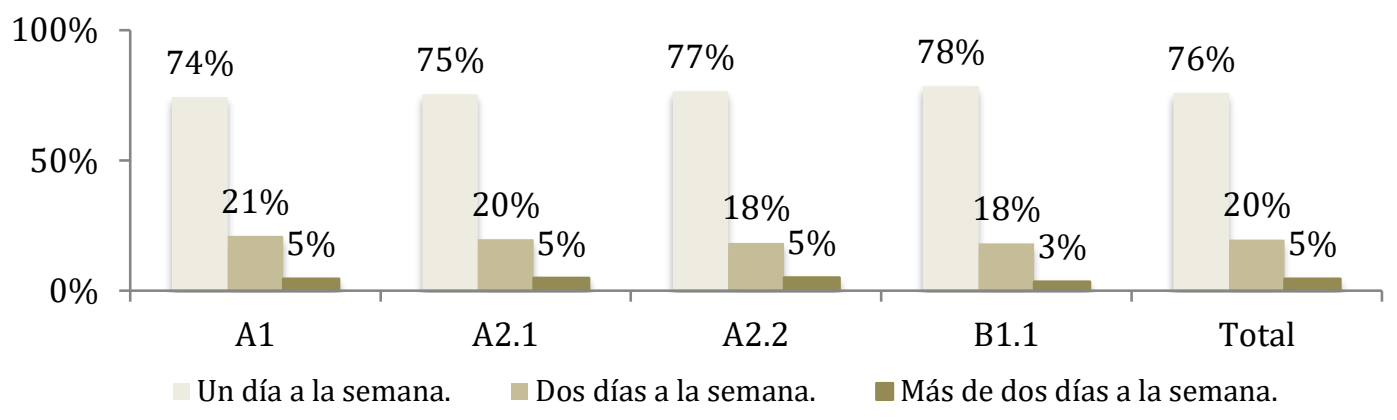

En cuanto a la autonomía de trabajo de los alumnos, el 65\% (1.894) señala requiere la ayuda puntual de sus padres o de otra persona mayor para realizar las actividades en línea. Este porcentaje, sumado al 16\% de aquellos que necesitan ayuda en todo momento, arroja un dato que consideramos relevante y es que el $81,5 \%$ de los alumnos requiere la colaboración de un adulto para la realización de las actividades, bien de manera puntual o continua. Solo un 18,5\% de los alumnos afirma ser autónomo o casi autónomo en estas tareas (Tabla 7 y Figura 4). De lo anterior se deriva que el compromiso de los padres se convierte en un elemento que influye decisivamente en el desarrollo de la modalidad en línea del programa y que creemos debe tenerse en cuenta en dos vertientes: por un lado, informando a los padres de la necesidad de este apoyo en el momento de la matriculación en el programa y por otro, ofrenciendo indicaciones y orientaciones dirigidas específicamente a los padres sobre los cursos (estructura, tipo de actividades, hábitos y consejos de trabajo en línea, etc.) que les sirvan para ayudar a sus hijos en la realización de estas actividades.

Tabla 7 /Figura 4: Grado de autonomía de los alumnos con las actividades en línea

\begin{tabular}{|c|c|c|c|}
\hline & \multicolumn{2}{|c|}{ Subtotales } & Total \\
\hline Sí, lo hago yo solo. & $539(18,5 \%)$ & & \\
\hline No, mis padres/otra persona mayor me ayudan un poco. & $1.894(65,2 \%)$ & 2.367 & (100\% \\
\hline No, mis padres/otra persona mayor me ayudan todo el tiempo & $473(16,3 \%)$ & $(81.5 \%)$ & \\
\hline
\end{tabular}

¿Trabajas en el ordenador tú solo?

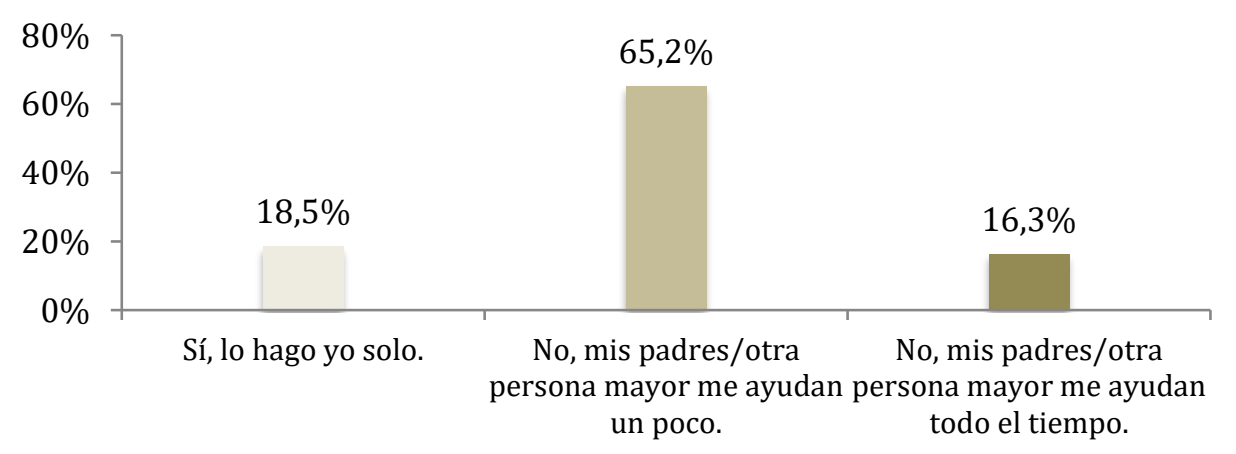


En la distribución de respuestas por edades (Figura 5), se observa que la línea que señala al alumno autónomo (opción "Sí, lo hago yo solo") asciende significativamente con la edad $(+60 \%)$, mientras descienden las otras dos líneas (ambas en torno a un $30 \%$ ) correspondientes al alumnado que señala requerir la ayuda de sus padres.

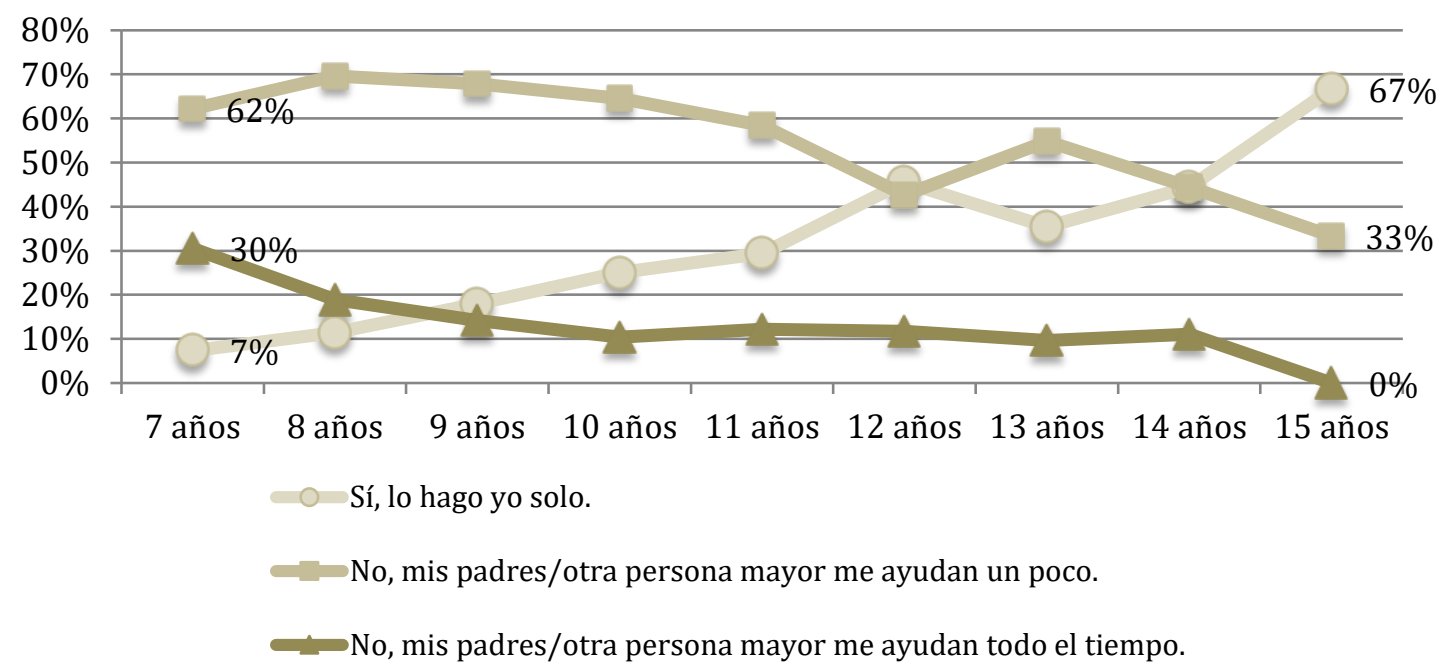

Figura 5: Evolución de la autonomía de trabajo, por edades.

En los datos obtenidos sobre la percepción sobre la dificultad de las actividades, se observa que la la mayoría de los alumnos (66\%) consideran que las actividades de Aula Internacional son fáciles. El $22 \%$ opina que son difíciles. A ambos lados se encuentran las opciones menos frecuentes: el 11\% piensa que las actividades son muy fáciles y solo a un $2 \%$ le resultan muy difíciles. (Tabla 8 y Figura 6).

Tabla 8 / Figura 6: Percepción sobre el grado de dificultad en las actividades Nivel

\begin{tabular}{r|r|r|r|r|r} 
& $\mathrm{A} 1$ & $\mathrm{~A} 2.1$ & $\mathrm{~A} 2.2$ & $\mathrm{~B} 1.1$ & Totales \\
\hline Muy fáciles. & $108(12 \%)$ & $94(11 \%)$ & $81(10 \%)$ & $28(7 \%)$ & $311(11 \%)$ \\
\hline Fáciles. & $544(62 \%)$ & $560(66 \%)$ & $547(70 \%)$ & $258(63 \%)$ & $1.909(66 \%)$ \\
\hline Difíciles. & $211(24 \%)$ & $176(21 \%)$ & $140(18 \%)$ & $114(28 \%)$ & $641(22 \%)$ \\
\hline Muy difíciles. & $11(1 \%)$ & $15(2 \%)$ & $10(1 \%)$ & $9(1 \%)$ & $45(2 \%)$ \\
\hline Totales & 874 & 845 & 778 & 409 & 2.906 \\
& & & $100 \%)$
\end{tabular}


"¿Las actividades te han parecido fáciles o difíciles?"

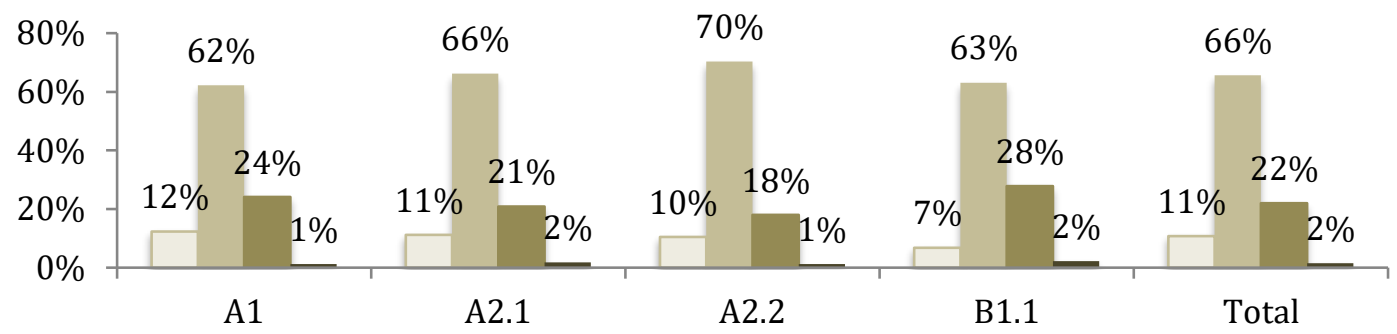

$\square$ Las actividades eran muy fáciles. $\quad$ Las actividades eran fáciles.

- Las actividades eran difíciles. $\quad$ Las actividades eran muy difíciles.

Agrupando los resultados de las cuatro opciones en solo dos categorías ("Fáciles o Muy fáciles", por una parte y "Difíciles o Muy difíciles", por otra) y por niveles (Figura 7) observammos que la percepción de facilidad va en ligero aumento en los tres cursos A (el curso A2.2 se percibe como ligeramente más fácil que A2.1, y éste, a su vez, más fácil que A1), tendencia que se modifica al llegar al nivel B1.1, donde desciende el valor en un $11 \%$ con respecto al anterior (A2.2), considerando los alumnos éste el nivel de mayor dificultad de los cuatro. Estos resultados, necesariamente junto con otros datos como las calificaciones obtenidas por los alumnos en las actividades de cada curso, pueden ser utilizados por el equipo de revisión de actividades para calibrar y ajustar, en su caso, la dificultad de determinadas actividades en línea para cada nivel.

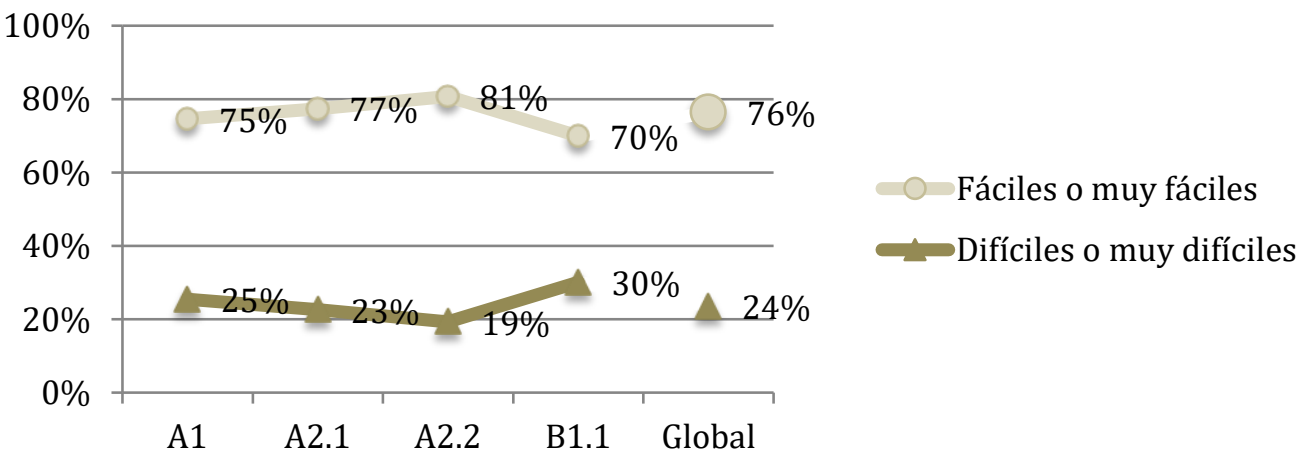

Figura 7: Percepción de dificultad, con respuestas agrupadas en dos opciones y por niveles.

En relación a la pregunta específica sobre incidencias/dificultades técnicas, el 79\% de los alumnos señala haberlas tenido; de este porcentaje, el $60 \%$ señala que las incidencias se han producido de manera esporádica y el 19\%, con mayor frecuencia (Tabla 9 y Figura 8).

Se observa una alta consistencia de las respuestas por niveles en comparación con los resultados globales. Este hecho, sumado a la circunstancia de que los destinatarios son alumnos en edad escolar y que, además, hayan manifestado en una 
de las preguntas este cuestionario requerir la ayuda de un adulto para la realización de actividades en línea, indica hacia la conveniencia de mejorar este aspecto en los cursos. Acudir a otras fuentes de información (datos internos de los cursos, feedback de tutores en línea, información del equipo del soporte técnico, etc.) podría ayudar a detectar el origen y tipo de estas incidencias técnicas. Otro factor que puede estar influyendo de en la alta prevalencia sobre la percepción de dificultades técnicas es la novedad que para un alto porcentaje de alumnos supone esta modalidad de enseñanza, y que podría estar relacionado con el $41 \%$ de alumnado que ha participado por primera vez en la modalidad en línea o, de modo general, con una posible escasa formación en el uso de plataformas y de herramientas informáticas.

Tabla 9 y Figura 8: Incidencias técnicas, por niveles

\begin{tabular}{|c|c|c|c|c|c|}
\hline & \multicolumn{4}{|c|}{ Nivel } & \multirow{2}{*}{ Total } \\
\hline & $\mathrm{A} 1$ & A2.1 & A2.2 & B1.1 & \\
\hline $\begin{array}{l}\text { No, nunca o casi nunca. Las actividades } \\
\text { funcionaban bien. }\end{array}$ & $\begin{array}{c}160 \\
(18 \%)\end{array}$ & $\begin{array}{c}170 \\
(20 \%)\end{array}$ & $\begin{array}{c}184 \\
(24 \%)\end{array}$ & $95(23 \%)$ & $609(21 \%)$ \\
\hline $\begin{array}{l}\text { Sí, algunas veces he tenido problemas } \\
\text { técnicos. }\end{array}$ & $\begin{array}{c}531 \\
(61 \%)\end{array}$ & $\begin{array}{c}504 \\
(60 \%)\end{array}$ & $\begin{array}{c}459 \\
(59 \%)\end{array}$ & $\begin{array}{c}227 \\
(56 \%)\end{array}$ & $\begin{array}{l}1.721 \\
(59 \%)\end{array}$ \\
\hline $\begin{array}{l}\text { Sí, muchas veces he tenido problemas } \\
\text { técnicos. }\end{array}$ & $\begin{array}{c}175 \\
(20 \%)\end{array}$ & $\begin{array}{c}157 \\
(19 \%)\end{array}$ & $\begin{array}{c}119 \\
(15 \%)\end{array}$ & $80(20 \%)$ & $531(18 \%)$ \\
\hline *En blanco & $8(1 \%)$ & $14(2 \%)$ & $16(2 \%)$ & $7(2 \%)$ & $45(2 \%)$ \\
\hline
\end{tabular}

¿Has tenido dificultades técnicas al hacer las actividades?

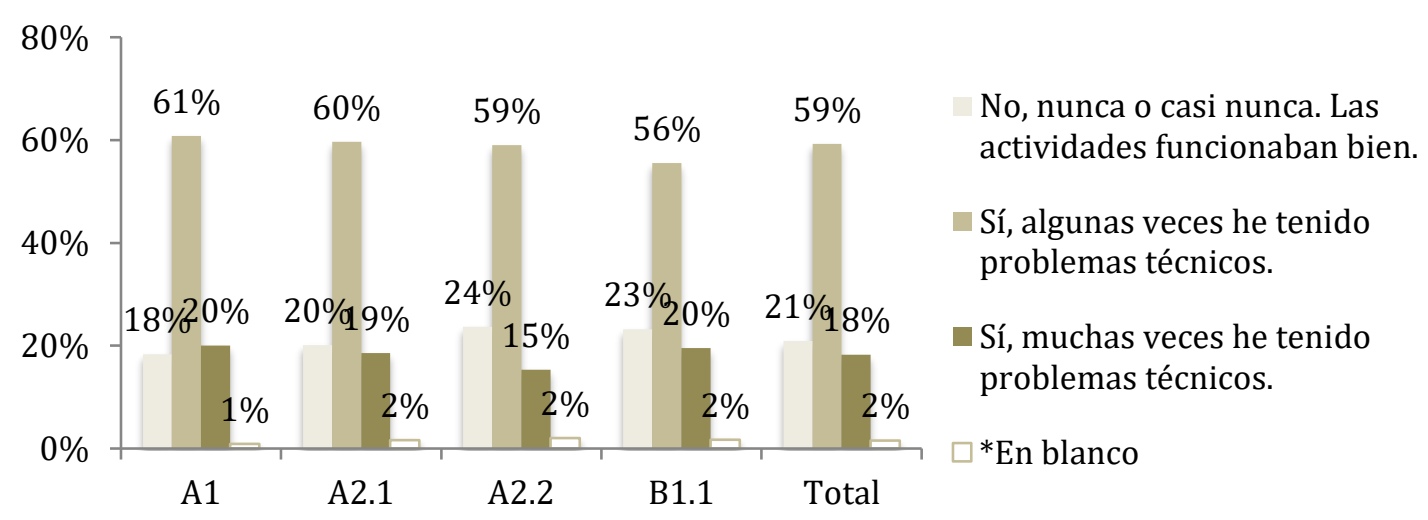

En relación a la percepción de los alumnos sobre su aprendizaje, la mayoría de los alumnos (53\%) perciben que han aprendido "muchas cosas". Le sigue en un porcentaje no muy inferior (43\%) las respuestas de alumnos que perciben haber aprendido "algunas cosas". Un tercer grupo muy reducido (4\%) señala que "casi no ha aprendido cosas" con las actividades en linea. (Figura 9). 


\section{¿Cuánto has aprendido con las actividades en línea?}

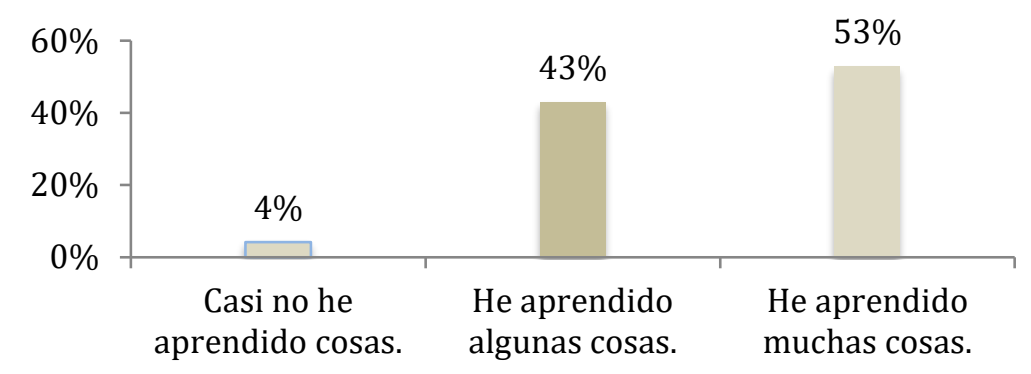

Figura 9: Percepción de aprendizaje, resultados globales.

En el análisis por niveles (Figura 10), mientras la opción de "Casi no he aprendido cosas" se mantiene en porcentajes inferiores al $10 \%$ y con una variación que consideramos no significativa, del 6\%, entre mínimo (A1: 2\%) y máximo (B1.1: 8\%), sí se observan diferencias reseñables entre las otras dos opciones: la proporción de alumnos que considera que ha aprendido muchas cosas desciende un $30 \%$ de manera continua desde A1 (64\%) hasta B1.1 (34\%) y de manera inversa, la opción de "He aprendido algunas cosas" asciende significativamente entre ambos extremos $(+24 \%)$.

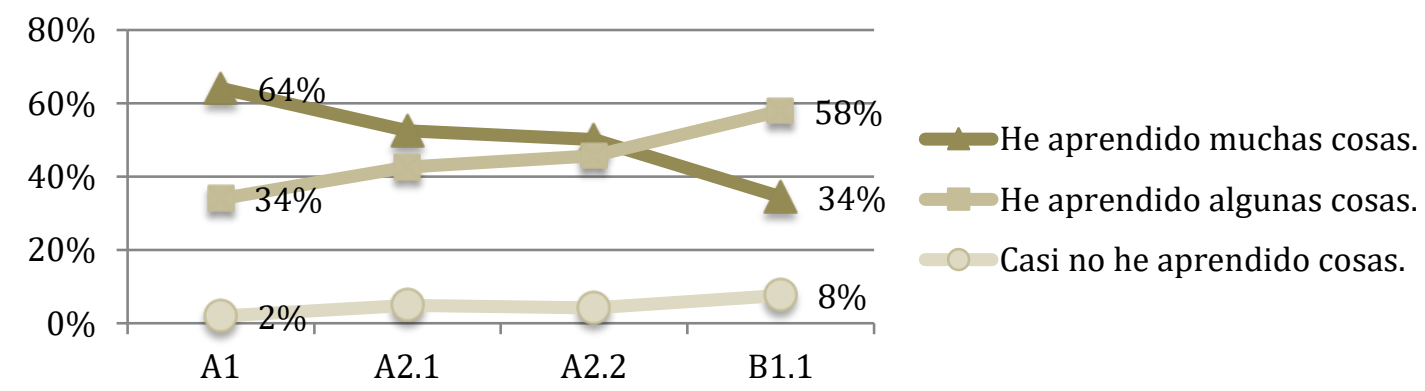

Figura 10: Percepción de aprendizaje, por niveles

En el análisis de las preferencias y gustos por actividades y por modalidad de aprendizaje, en la pregunta de si les ha gustado realizar las actividades en línea, la respuesta más frecuente de las cuatro opciones es "Me ha gustado", con un 39\%. La siguiente opción elegida es "Me ha gustado un poco", con un $27 \%$ y muy seguida de esta última, se encuentra la opción de "Me ha gustado mucho" (24\%) (Figura 11). Dado que las tres opciones forman parte de un continuo sobre la disposición para realizar las actividades en línea, aunque obviamente, cada una en un grado diferente, consideramos que los datos obtenidos en esta pregunta son globalmente un resultado positivo para la modalidad en línea del programa, en la medida que la mayoría de los destinatarios finales del programa afirma que le gusta realizar las actividades en esta modalidad. 
¿Te ha gustado hacer las actividades en línea?

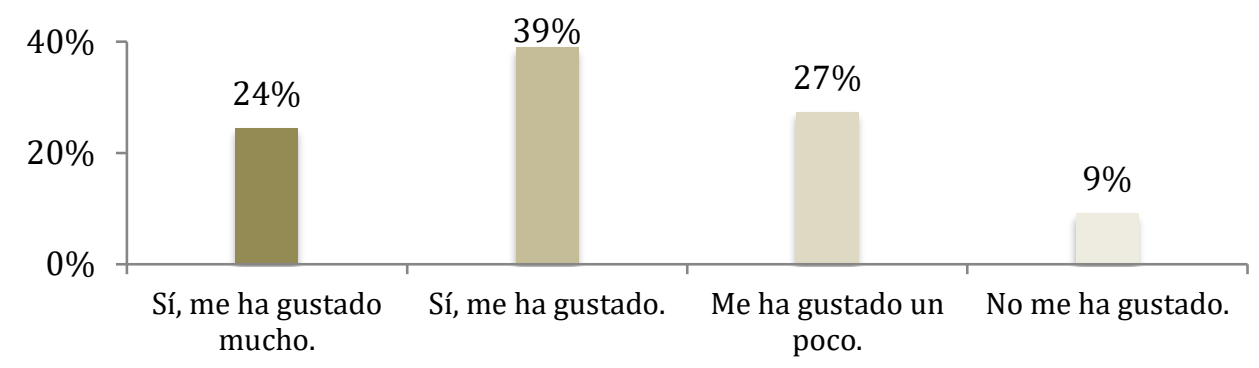

Figura 11: Disposición de los alumnos hacia las actividades en línea.

En el análisis de las respuestas por niveles y edades, y habiendo seleccionado para ello la franja de 7 a 11 años, por ser la que más porcentaje de alumnos matriculados en el programa, se encuentran tendencias reseñables (Figura 12 y Tabla 9). La opción que más destaca por su diferencia de porcentaje entre valores máximo y mínimo es la de "Me ha gustado mucho", al descender en un 18\%. La respuesta que globalmente arroja los datos más elevados, "Me ha gustado", se mantiene en un porcentaje muy similar en los cuatro niveles y edades, mostrando un leve ascenso en A2.2.

Figura 12 / Tabla 9: Disposición de los alumnos hacia las actividades en línea, por edades.

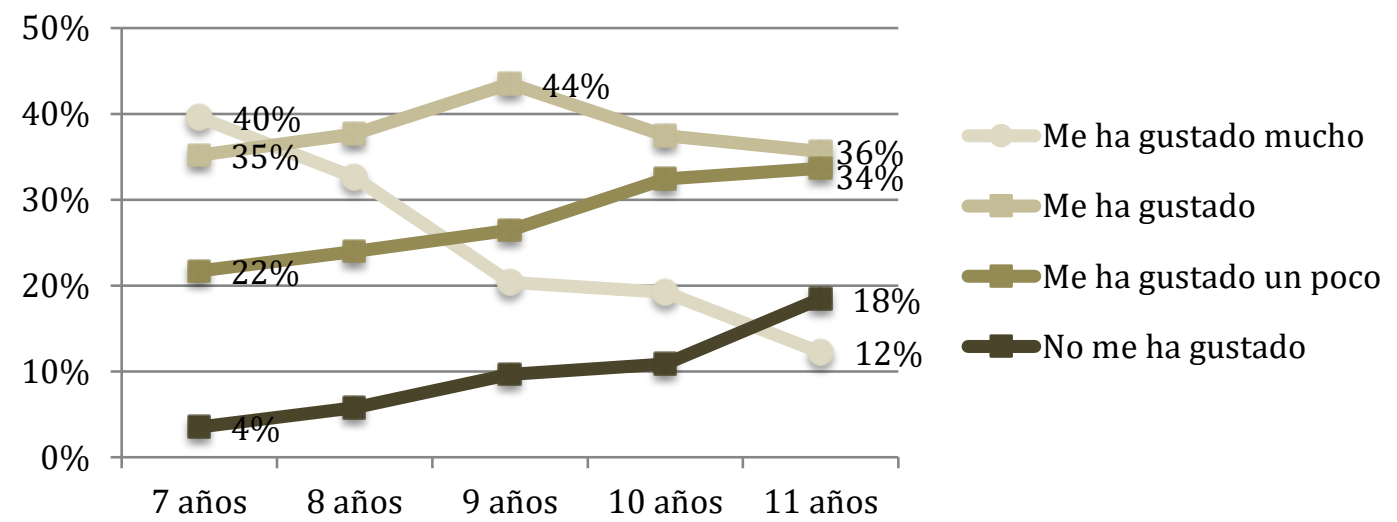

\begin{tabular}{l|r|r|r|r|r} 
& 7 años & 8 años & 9 años & \multicolumn{1}{c|}{10 años } & 11 años \\
\hline Me ha gustado mucho. & $135(40 \%)$ & $260(33 \%)$ & $154(20 \%)$ & $115(19 \%)$ & $37(12 \%)$ \\
\hline Me ha gustado. & $120(35 \%)$ & $300(38 \%)$ & $329(44 \%)$ & $224(37 \%)$ & $108(36 \%)$ \\
\hline Me ha gustado un poco. & $74(22 \%)$ & $191(24 \%)$ & $200(26 \%)$ & $194(32 \%)$ & $102(34 \%)$ \\
\hline No me ha gustado. & $12(4 \%)$ & $46(6 \%)$ & $73(10 \%)$ & $65(11 \%)$ & $56(18 \%)$ \\
\hline Subtotales por edad & 341 & 797 & 756 & 598 & 303 \\
\hline
\end{tabular}

Por último cabe destacar la opción "No me ha gustado" pues muestra igualmente 
una variación sustancial, ascendente por niveles y edades; comenzando en 5\% y llegando al $18 \%$ en los 11 años. Por lo contrario, en la última de las opciones, que recogía explícitamente la respuesta de "No me ha gustado", obtiene un porcentaje del 9\%, sustancialmente inferior a cualquiera de las tres anteriores. Con todo lo anterior, podríamos concluir que los datos apuntan a que, en líneas generales, a la mayoría de los alumnos les gusta realizar las actividades en línea; sin embargo, es destacable la evolución de esta variable entre niveles y edades: el gusto por realizar las actividades en línea va descendiendo a medida que se asciende en nivel y edad.

En la pregunta abierta sobre lo que más les gusta de Aula Internacional, se obtuvieron 2.602 respuestas que, mediante su análisis de contenido, fueron clasificadas en 8 categorías y 58 subcategorías. En la Figura 13 se muestran las diez subcategorías más frecuentes.

¿Qué es lo que más te gusta de Aula Internacional?

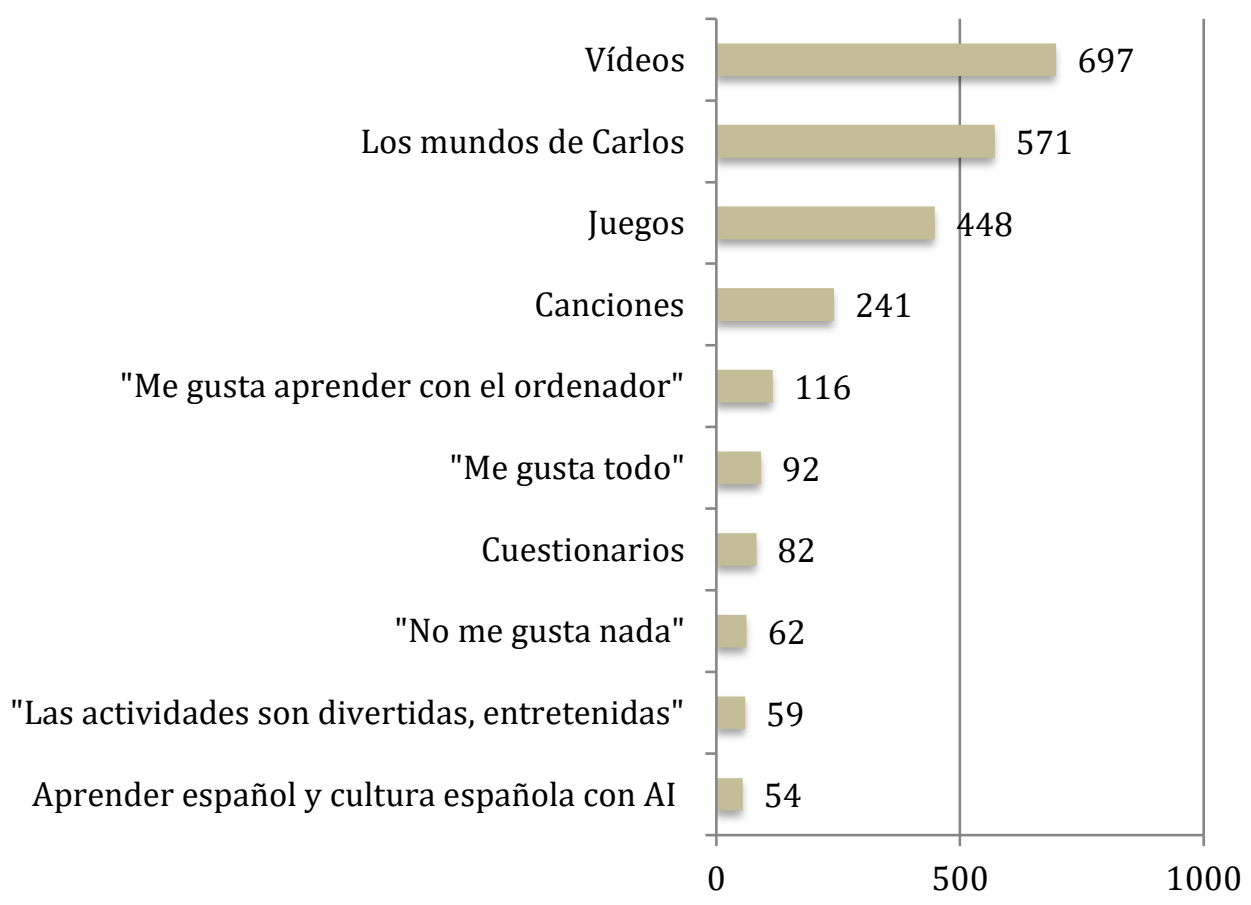

Figura 13: Las diez subcategorías más frecuentes en la pregunta abierta sobre "Lo que más me gusta de Aula Internacional".

Destaca la alta frecuencia de las cuatro primeras subcategorías, referidas a actividades generales (Vídeos, Juegos, Canciones) o específicas ("Los mundos de Carlos", un portal de actividades en línea del Instituto Cervantes, denominada 
exactamente "Mi mundo en Palabras"8). En un grupo de subcategorías menos frecuentes, los alumnos aluden otro tipo de actividades (Cuestionarios), a aspectos de disposición positiva relacionados con el aprendizaje a través del ordenador, y con la lengua española. Otras respuestas incluyen la totalidad "Me gusta todo" o lo contrario, "No me gusta nada", o alusiones específicas hacia el aspecto lúdico y de diversión en las actividades.

En la pregunta abierta sobre lo que menos les gusta de Aula Internacional, se obtuvieron 2.454 respuestas, que fueron clasificadas en 8 categorías y 64 subcategorías. En la Figura 14 se muestran las diez subcategorías más frecuentes.

¿Qué es lo que menos te gusta de Aula Internacional?

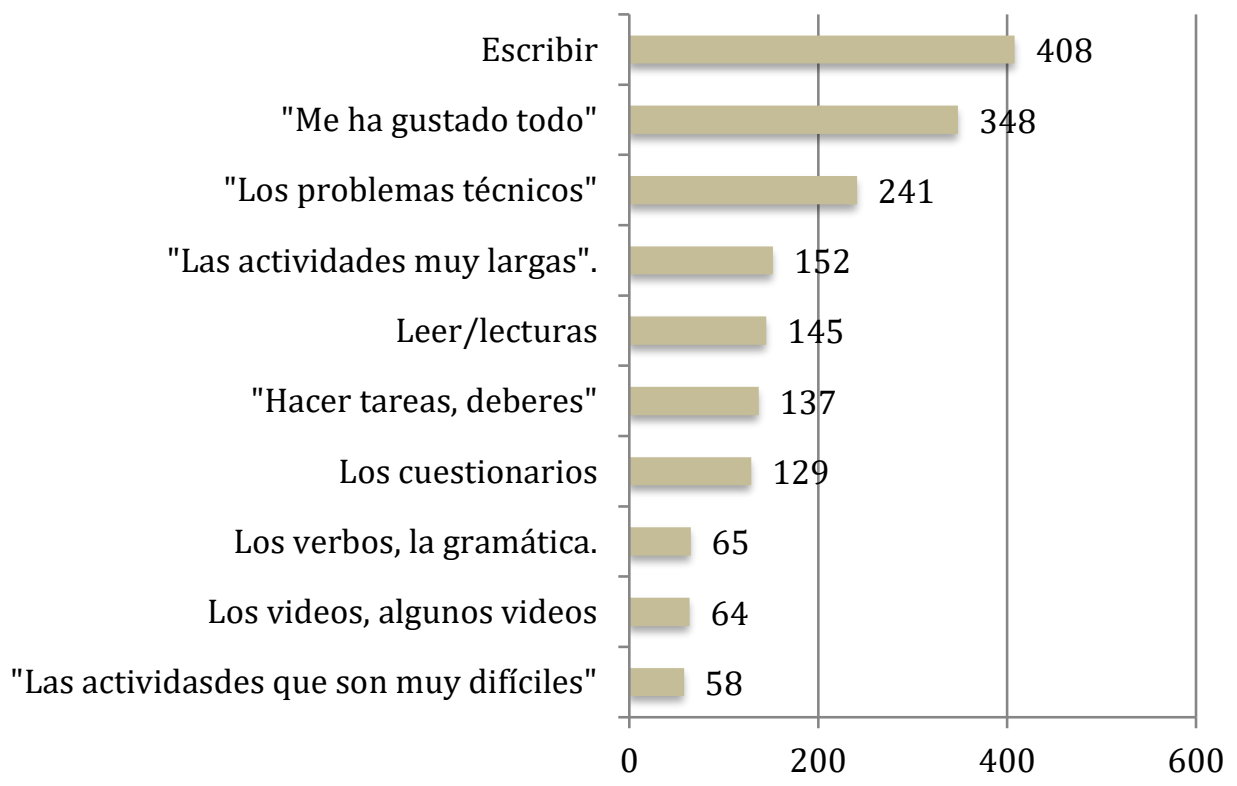

Figura 14: Las diez subcategorías más frecuentes en la pregunta abierta sobre "Lo que menos me gusta de Aula Internacional".

Se observa que las destrezas relacionadas con la lectura y escritura aparecen entre las cinco primeras respuestas como las menos preferidas por los alumnos. Un grupo de alumnos igualmente muy numeroso especifica que, contrariamente a la redacción de la pregunta, "Les ha gustado todo de $\mathrm{AI}^{\prime}$, lo cual reafirma su buena disposición hacia la enseñanza en línea. Les siguen las dificultades técnicas como el aspecto que menos les ha gustado. También mencionan caracterísiticas específicas de las actividades "muy largas" o "muy difíciles". Otro grupo de alumnos señala las "tareas o deberes" como lo que menos les gusta, respuesta de difícil interpretación para discernir si se refieren a las propias actividades en línea o bien a los deberes de las clases presenciales. En un último 
grupo de respuestas, menos numerosas dentro de esta selección de diez, podríamos agrupar las que aluden a actividades generales (Cuestionarios, Vídeos) y contenidos específicos (verbos y gramática).

En la última pregunta de este bloque, sobre preferencia de actividades y destrezas específicas, en este caso, a través de una pregunta cerrada, con 4 opciones (Tabla 10 y Figura 15), la preferencia por el visionado de vídeos es significativamente la más alta en relación a las otras tres, con un porcentaje del 62\%, en comparación con el resto: 20\% Escuchar canciones; $13 \%$ Escribir palabras y textos; 5\% Leer textos. Se observa asimismo en los datos una alta consistencia por niveles, tanto en el orden de las cuatro opciones de respuesta como en los porcentajes obtenidos.

Tabla 10 / Figura 15: Preferencia de destrezas en las actividades.

\begin{tabular}{|c|c|c|c|c|c|}
\hline & \multicolumn{4}{|c|}{ Nivel } & \multirow{2}{*}{ Total } \\
\hline & A1 & A2.1 & A2. 2 & B1.1 & \\
\hline Ver vídeos & $\begin{array}{r}567 \\
(65 \%)\end{array}$ & $\begin{array}{r}500 \\
(59 \%)\end{array}$ & $\begin{array}{r}482 \\
(62 \%)\end{array}$ & $\begin{array}{r}259 \\
(63 \%)\end{array}$ & $\begin{array}{r}1.808 \\
(62 \%)\end{array}$ \\
\hline $\begin{array}{l}\text { Escuchar } \\
\text { canciones }\end{array}$ & $\begin{array}{r}177 \\
(20 \%)\end{array}$ & $\begin{array}{r}188 \\
(22 \%)\end{array}$ & $\begin{array}{r}147 \\
(19 \%)\end{array}$ & $62(15 \%)$ & $574(20 \%)$ \\
\hline $\begin{array}{l}\text { Escribir palabras y } \\
\text { frases con el } \\
\text { teclado }\end{array}$ & $94(11 \%)$ & $\begin{array}{r}117 \\
(14 \%)\end{array}$ & $\begin{array}{r}107 \\
(14 \%)\end{array}$ & $59(14 \%)$ & 377 (13\%) \\
\hline Leer textos & $36(4 \%)$ & $40(5 \%)$ & $42(5 \%)$ & $29(7 \%)$ & $147(5 \%)$ \\
\hline
\end{tabular}

Elige lo que más te gusta hacer

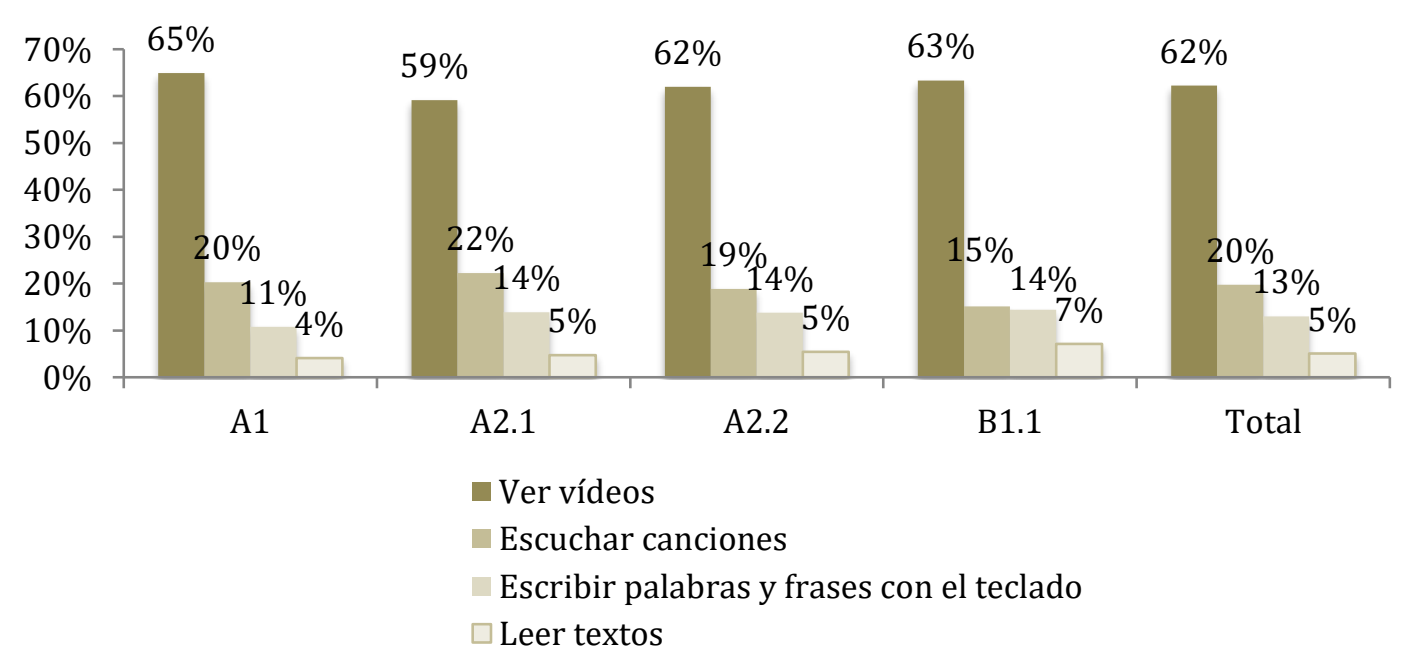

Todo ello apunta a que las actividades vinculadas a destrezas visuales (Ver vídeos) y auditivas (Escuchar canciones y Ver vídeos, en los que hay siempre un componente 
sonoro) son las preferidas por los alumnos, por delante de aquellas relacionadas con destrezas de escritura y la lectura, en tercer y cuarto lugar, jerarquización que coincide además con las respuestas abiertas en las dos preguntas anteriores, donde los "Vídeos" y las "Canciones" ocupaban los primeros puestos en sus respuestas a lo que más les gustaba de Aula Internacional, mientras que "Escribir" y "Leer/Lecturas" aparecían entre las respuestas con mayor frecuencia sobre lo que menos les gustaba.

En la preferencia por la modalidad de enseñanza o en este caso, de aprendizaje por parte de los alumnos (Figura 16), la opción que señalan con mayor frecuencia es la semipresencial, como combinación de las dos formas de aprendizaje, con un 45\%. Le sigue la preferencia por la modalidad presencial (39\%) y por último, con una diferencia sustancial con respecto a las dos opciones anteriores, está el grupo de alumnos que prefiere la modalidad puramente en línea (16\%). Consideramos que estos resultados son globalmente positivos para el desarrollo de la semipresencial en el programa en la medida que la modalidad en línea es, según los datos globales, altamente aceptada por la mayoría de los alumnos, tanto por el grupo que prefiere esa modalidad específica por el grupo que señala su preferencia por la combinación de ambas modalidades.

Para aprender español, ¿qué prefieres?

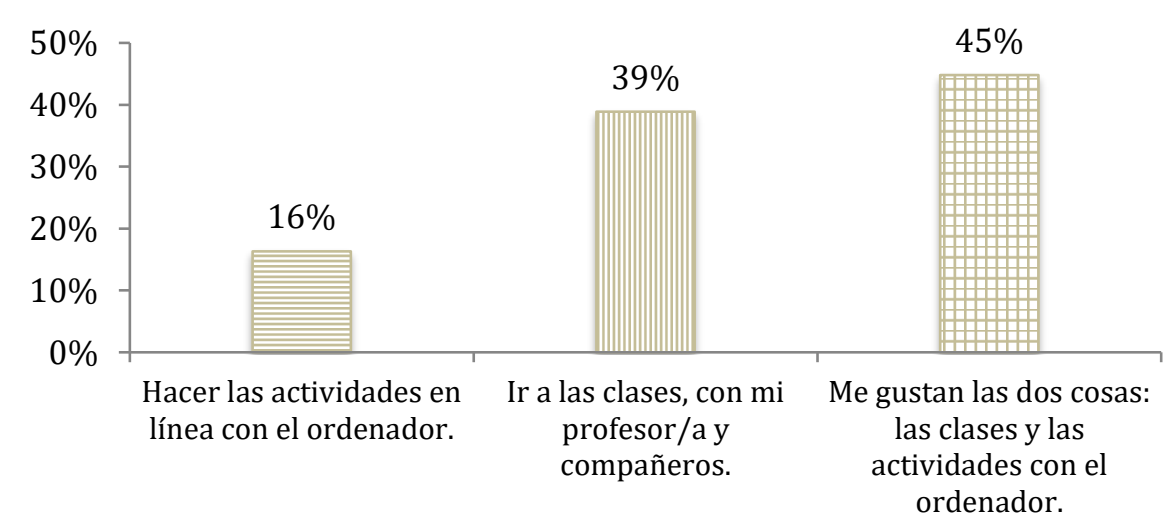

Figura 16: Preferencia por modalidad de aprendizaje

Por edades se observan ciertas diferencias con respecto a la distribución global (Tabla 11 y Figura 17). En este caso, aunque los valores de preferencia por la modalidad en línea se mantienen muy estables en todos las edades (valores entre el 14 y $18 \%$ ), se observa claramente un cambio en las otras dos opciones: a medida que asciende el nivel, la preferencia por las clases presenciales es muy marcada, con un ascenso progresivo 
por edades y diferencias poncentuales de un $20 \%$ entre los valores extremos, así como en un descenso de la misma proporción en la preferencia por la semipresencialidad. Todo ello apunta a que a medida que los alumnos avanzan en edad, aumenta su preferencia por las clases presenciales.

Tabla 11 y Figura 17: Evolución de la preferencia modalidad de aprendizaje, por edades

\begin{tabular}{l|c|c|c|c|c} 
& 7 años & 8 años & 9 años & 10 años & 11 años \\
\hline Hacer las actividades en línea con el & 56 & 110 & 124 & 105 & 53 \\
ordenador. & $(16 \%)$ & $(14 \%)$ & $(16 \%)$ & $(18 \%)$ & $(17 \%)$ \\
\hline Ir a las clases, con mi profesor/a y & 104 & 265 & 300 & 256 & 149 \\
compañeros. & $(30 \%)$ & $(33 \%)$ & $(40 \%)$ & $(43 \%)$ & $(49 \%)$ \\
\hline Me gustan las dos cosas: las clases y & 181 & 422 & 332 & 237 & 101 \\
las actividades con el ordenador. & $(53 \%)$ & $(53 \%)$ & $(44 \%)$ & $(40 \%)$ & $(33 \%)$ \\
\hline Totales por edad & 341 & 797 & 756 & 598 & 303 \\
\hline
\end{tabular}

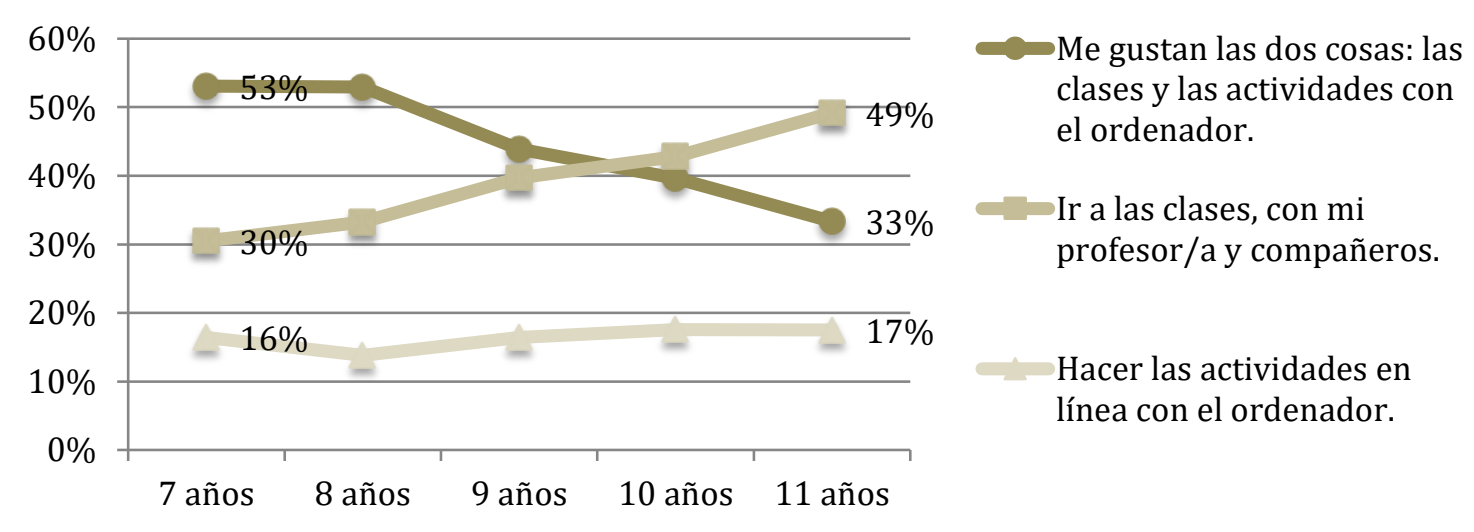

En la pregunta abierta y voluntaria dirigida a los padres, a través de la cual podían manifestar sus valoraciones y comentarios sobre Aula Internacional, se obtuvieron 1.503 respuestas, que fueron clasificadas en 7 categorías y 83 subcategorías, con carácter no excluyente, por lo que el total de evidencias clasificadas sumaron 2.980. En la Figura 18 se muestran las diez subcategorías más frecuentes.

Las respuestas de los padres a esta pregunta se convierten en una segunda fuente de información indirecta pero muy valiosa, en la medida que ofrece un feedback desde una perspectiva diferente a los alumnos y con información muy variada y para cuyo análisis de contenido fue necesaria una muy amplia subcategorización.

Las respuestas relacionadas con las incidencias técnicas se engloban en la categoría con mayor frecuencia $(\mathrm{N}=369)$. Este dato confirma lo expresado por los alumnos en dos de las preguntas anteriores en la encuesta. Le siguen una categoría con comentarios que incluyen una valoración positiva de Aula Internacional $(N=329)$ y una 
tercera $(\mathrm{N}=200)$ corresponde a agradecimientos explícitos hacia los tutores, profesores y hacia el programa. La cuarta subcategoría incluye las respuestas referidas a la preferencia de un grupo de padres por la modalidad presencial $(N=171)$. Como se puede observar en la Figura 18, las siguientes categorías se relacionan tanto con aspectos de disposición de sus hijos hacia el aprendizaje en línea "le ha gustado", "ha aprendido cosas", detalles sobre aspectos de estudio en casa "nos falta tiempo para realizar las actividades", autonomía de trabajo "mi hijo necesita mi ayuda" u otros sobre funcionaminento de las actividades "la plataforma ha mejorado" o valoración de la modalidad en línea en la medida que complementa a la presencial.

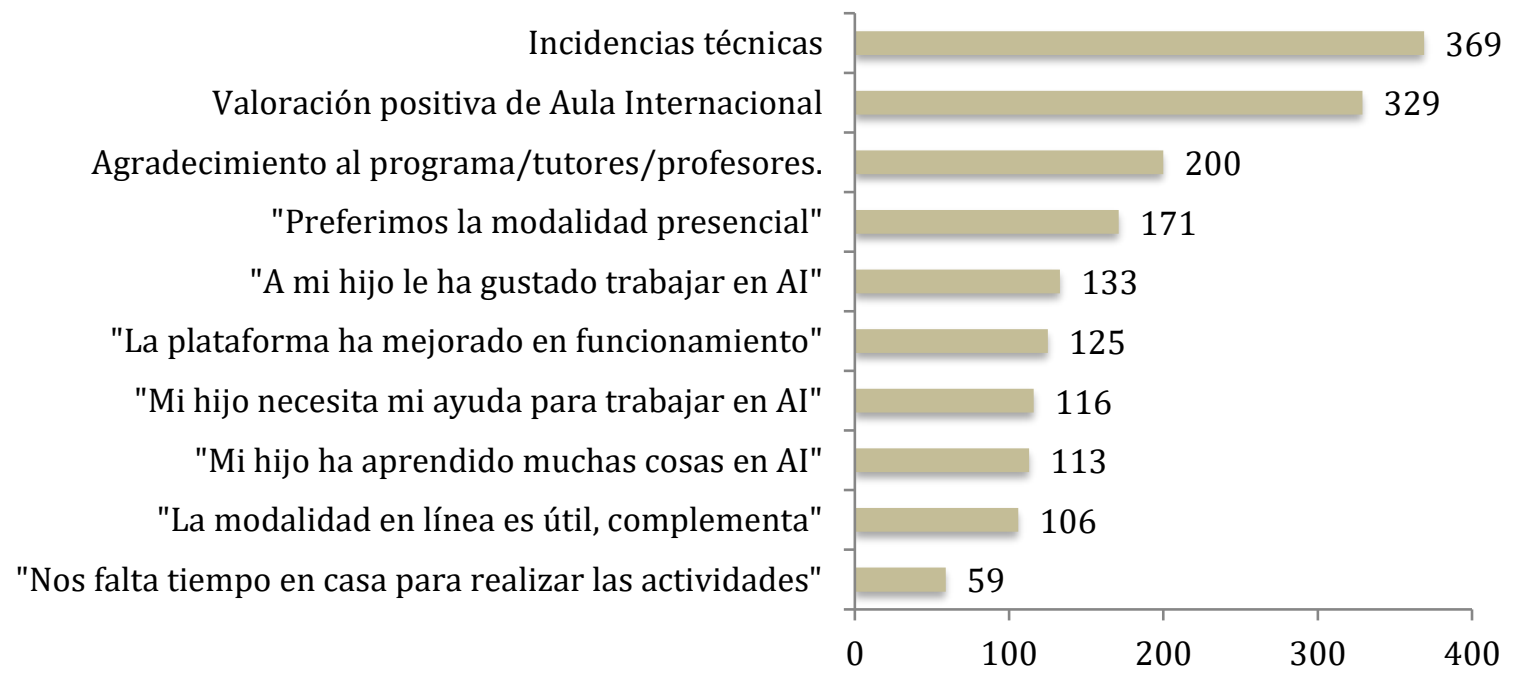

Figura 18: Las diez subcategorías más frecuentes de los padres de alumnos.

\section{Conclusiones}

De modo general, se puede concluir que la información obtenida es valiosa para el programa al ofrecer un feedback de los destinatarios finales del programa y que, dada la amplia muestra recogida, adquiere un alto nivel de representatividad.

En relación a los hábitos de trabajo en línea y la prevalencia mayoritaria de un solo día a la semana para la realización de estas actividades, podría ser interesante en posteriores estudios obtener información más precisa en cuanto a tiempo real que emplean los alumnos en estas tareas y poder compararlo con el tiempo programado por la normativa, así como las razones que llevan a algunos alumnos a realizar las actividades en días diferentes. Dada a la edad de los alumnos, quizás fuera necesario 
acudir a la fuente de los padres para obtener información más precisa sobre este aspecto (por ejemplo, en términos de horas-minutos).

El hecho de que la mayoría de los alumnos requiera la ayuda de sus padres a la hora de realizar las actividades en línea creemos que puede ser tenido en cuenta por el programa de cara a ofrecer una información previa sobre este aspecto hacia las familias que matriculan a sus hijos en el programa así como un apoyo técnico y con estrategias de trabajo a los padres durante todo el curso. Con independencia de lo anterior, es destacable la progresión observada en la autonomía de trabajo en línea de los alumnos por edades y niveles.

El umbral de dificultad de las actividades percibido por los alumnos podría valorarse como bajo, pues en general las actividades les resultan fáciles o muy fácilles. Esta percepción evoluciona ligeramente por niveles: en el nivel A la percepción de facilidad aumenta con el nivel, cambiando la tendencia al llegar al nivel B1.1. Estos datos deben ser necesariamente contrastados con otras fuentes (datos internos de la plataforma con las calificaciones de las actividades) en el caso que se observe necesario desde el programa ajustar los niveles de dificultad en las actividades planteadas.

Las actividades más valoradas por los alumnos son aquellas vinculadas a destrezas visuales (ver vídeos) y auditivas (escuchar canciones), en claro contraste con las de lectura y escritura. Los equipos de elaboración y materiales del programa pueden tener en cuenta la no preferencia explícitamente manifestada por los alumnos hacia las actividades relacionadas con la escritura y la lectura, con el fin de realizar una selección y diseño más cuidado y atrayente para contribuir a que los ejercicios y actividades que incluyan este tipo de destrezas, tan importantes en el aprendizaje de una lengua, sean realizadas con mayor entusiasmo y motivación por parte de los alumnos.

La alta prevalencia en la percepción de dificultades o incidencias técnicas es manifestada por los alumnos y padres, y se observa de forma global y en el análisis por niveles. Un análisis de contenido más pormenorizado en las respuestas de los padres así como de datos internos en las actividades de la plataforma podrían aportar detalles sobre el origen y tipo de estas incidencias técnicas con el objetivo de resolverlas o en su caso, minimizarlas. Un factor que puede estar influyendo en este aspecto sería la novedad de esta modalidad de enseñanza para los alumnos que se enfrentan por primera vez al uso de una plataforma (que durante el curso 2014-15 ha supuesto casi la mitad de los 
participantes) o, de forma general, una posible falta de formación en el uso de plataformas y de herramientas informáticas de los usuarios.

La percecpción de aprendizaje hacia la modalidad en línea por parte de los alumnos es globalmente positiva, quienes manifiestan de forma mayoritaria que "les gusta realizar las actividades", considerando igualmente que "han aprendido muchas cosas". Dos de las categorías en las respuestas abiertas de los padres apoyan ambas percepciones. Es destacable, no obstante, la tendencia descendente de esta predisposición a medida que asciende la edad de los alumos y su nivel de adscripción en el programa.

En términos generales se puede hablar de una satisfacción del alumnado con la modalidad en línea y por tanto, con la semipresencial, observándose un cambio de preferencia hacia la modalidad presencial con la edad, que podría estar relacionada con la entrada en la etapa de socialización de los alumnos.

Se estima conveniente la triangulación de estos datos con los procedentes de los cursos en línea de la plataforma (calificaciones de alumnos, grado de participación en las actividades propuestas y en los foros de comunicación, consistencia de estos datos entre niveles y países, etc.) así como los procedentes de los profesores que imparten estas enseñanzas, para obtener una visión más completa de la implantación de esta modalidad de enseñanza.

\section{Notas}

${ }^{1}$ Enseñanza Secundaria para Personas Adultas

${ }^{2}$ A través de la Consejería de Educación en Andalucía http://www.juntadeandalucia.es

${ }^{3}$ A través de las Escuelas Oficiales de Idiomas en las Consejerías de Andalucía y Canarias o en los Departamentos de Idiomas de universidades.

${ }^{4}$ Correspondiente a educación primaria y secundaria obligatoria en EEUU.

${ }^{5}$ Otras clasificaciones sobre temáticas de investigación en b-learning se pueden encontrar en Drysdale et al. (2013), Halverson et al. (2012, 2014) y Bliuc et al. (2007).

${ }^{6}$ Revisada posteriormente en Christensen, Horn y Skater (2013).

7 Artículo 1 de la Orden EDU/3122/2010, de 23 de noviembre, por la que se regulan las enseñanzas complementarias de Lengua y Cultura españolas para alumnos españoles residentes en el exterior y se establece el currículo de las mismas. BOE 3 de diciembre, 2010 
${ }^{8}$ http://cvc.cervantes.es/ensenanza/mimundo/mimundo/default.HTML

\section{Referencias}

Acín, A. B. (2014). La educación secundaria de adultos en la actualidad. Un estudio comparado entre Córdoba (Argentina) y Cataluña (España). Disponible en http://hdl.handle.net/2445/54544

Area, M., Sanabria, A., y González, M. (2008). Análisis de una experiencia de docencia universitaria semipresencial desde la perspectiva del alumnado. RIED. Revista iberoamericana de educación a distancia, http://dx.doi.org/10.5944/ried.1.11.963

Bliuc, A. M., Goodyear, P., y Ellis, R. A. (2007). Research focus and methodological choices in studies into students' experiences of blended learning in higher education. The Internet and Higher Education, 10(4), 231-244. doi:10.1016/j.iheduc.2007.08.001

Bricall, J.M., (2000). Informe Universidad 2000. CRUE, Madrid. Disponible en http://www. crue. upm. es.

Brook, I., Beauchamp, G., y Campus L. (2015). A study of final Year Education Studies Undergraduate Students' Perceptions of Blended Learning within a Higher Education course. Educational futures (2015). Disponible en http://educationstudies.org.uk/wp-content/uploads/2015/01/Brook-andBeauchamp.pdf

Christensen, C. M., Horn, M. B., y Skater H. (2013). Is K-12 Blended Learning Disruptive? An introduction of the theory of hybrids. Clayton Christensen Institute. Disponible en http://www. christenseninstitute. org/wp-content/uploads/2013/05/Is-K-12Blended-Learning-Disruptive. pdf.

Clark, T., y Barbour, M. K. (2015). Online, Blended and Distance Education: Building Successful School Programs. Sterling, VA: Stylus Publishers.

de Cos Ruiz, F. J. (2009). Aprovechamiento didáctico de los módulos de comunicación del campus virtual en la enseñanza semipresencial de asignaturas de base lingüística. Edutec. Revista electrónica de tecnología educativa, (29). Disponible en http://www.edutec.es/revista/index.php/edutec-e/article/view/450/184 
Drysdale, J. S., Graham, C. R., Halverson, L. R., \& Spring, K. J. (2013). Analysis of research trends in dissertations and theses studying blended learning. Internet and Higher Education, 17 (1), 90-100. doi:10.1016/j.iheduc.2012.11.003

Dziuban, C. D., Hartman, J. L., Moskal, P. D. (2004). Blended Learning. Educase. 2004, 7. Disponible en http://net. educause. edu/ir/library/pdf/erb0407. pdf.

Fernández, Á. M. (2013). Las plataformas virtuales en la enseñanza semipresencial de adultos. Repositorio institucional de la Universidad de Almería. Disponible en http://hdl.handle.net/10835/2104

Galán, B. M., y Rodríguez Mateos, D. (2012). La evaluación de la formación universitaria semipresencial y en línea en el contexto del EEES mediante el uso de los informes de actividad de la plataforma Moodle. RIED. Revista iberoamericana de educación a distancia, 15(1). http://dx.doi.org/10.5944/ried.1.15.782

Graham, C. R. (2013). Emerging practice and research in blended learning. Handbook of distance education, 3. Routledge.

Griful, E., Gibert, J., y Sallan, J. M. (2005). Un modelo de blended learning en la Universidad Politécnica de Catalunya: la docencia semipresencial de la titulación de Ingeniería en Organización Industrial en la ETSEIT. En IX Congreso de Ingeniería de Organización (p. 48). Disponible en http://adingor.es/congresos/web/articulo/detalle/a/1024

Halverson, L. R., Graham, C. R., Spring, K. J., \& Drysdale, J. S. (2012). An analysis of high impact scholarship and publication trends in blended learning. Distance Education, 33(3), 381-413. DOI: 10.1080/01587919.2012.723166

López, J. M. S., Flores, M. F., y González, J. L. G. (2012). Descubriendo Edmodo: beneficios del microblogging en educación en adultos. Campo abierto: Revista de educación, 31(2), 53-70.

López, M., Sobrino, C., Barrajón, E., y Gallego, D. (2013). Tutorial de la Plataforma Multimedia para la docencia virtual, presencial y semipresencial. Disponible en http://hdl.handle.net/10045/43089

Martínez Mediado, C. (coord.) (2004). Técnicas e instrumentos de recogida y análisis de datos. UNED. Madrid.

Nó, Javier (2005). Planificación de la enseñanza semipresencial: una experiencia con posgrado. En: DUART, Josep M.; LUPIÁÑEZ, Francisco (coords.). Las TIC en la 
universidad: estrategia y transformación institucional. Revista de Universidad y Sociedad del Conocimiento (RUSC). Vol. 2, núm. 1. UOC. Disponible en http://dialnet.unirioja.es/ejemplar/111110

Osguthorpe, R. T., y Graham, C. R. (2003). Blended Learning Environments: Definitions and Directions. Quarterly Review of Distance Education, Vol. 4, Num. 3 p. 22733. ISSN-1528-3518

Pallisé, J. S. (2013) Estado actual de la semipresencialidad con relación a las TIC en veinte universidades europeas. Revista EDUTEC. ISBN 9789968969550

Pedró, F. (2015) ¿Quién da más? La innovación en la enseñanza superior y en la escuela. Telos: Cuadernos de comunicación e innovación, (101), 92-94.

Pinto Llorente, A. M. (2012). Resumen de tesis. Análisis de un modelo hipermedia modular para la enseñanza del inglés en modalidad semipresencial. Repositorio de la Universidad de Salamanca.

Poon, J. (2013). Blended Learning: An Institutional Approach for Enhancing Students' Learning Experiences. Journal Of Online Learning \& Teaching, 9, 2, pp. 271-289. Disponible en http://hdl.handle.net/10536/DRO/DU:30057995

Singh, H. (2006). Blended learning and work, en Bonk, C. J. y Graham, C. R. (2006). The handbook of blended learning: Global perspectives, local designs. San Francisco, CA: Pfeiffer Publishing.

Staker H., y M. B. Horn (2012): Classifying K-12 blended learning. Innosight Institute. Toboso, S. (2010). Formación del profesorado en educación musical a través de enseñanza semipresencial: un estudio de casos. Cultura y Educación, 22(4), 491505. DOI: $10.1174 / 113564010793351858$

Torrandell, I. y Noguera, M. (1999). Experiencia en la utilización telemática en un modelo de enseñanza semipresencial. Comunicación presentada en Edutec, 99. Disponible en http://tecnologiaedu.us.es/cuestionario/bibliovir/gte39.pdf 